\title{
Erratum to: Complete genome sequence of Pirellula staleyi type strain (ATCC $27377^{\mathrm{T}}$ )
}

Alicia Clum ${ }^{1}$, Brian J. Tindall ${ }^{2}$, Johannes Sikorski ${ }^{2}$, Natalia Ivanova ${ }^{1}$, Konstantinos Mavromatis ${ }^{1}$, Susan Lucas ${ }^{1}$, Tijana Glavina Del Rio ${ }^{1}$, Matt Nolan' ${ }^{1}$, Feng Chen ${ }^{1}$, Hope Tice ${ }^{1}$, Sam Pitluck', Jan-Fang Cheng ${ }^{1}$, Olga Chertkov ${ }^{1,3}$, Thomas Brettin ${ }^{1,3}$, Cliff Han ${ }^{1,3}$, John C. Detter $^{1,3}$, Cheryl Kuske ${ }^{1,3}$, David Bruce ${ }^{1,3}$, Lynne Goodwin ${ }^{1,3}$, Galina Ovchinikova ${ }^{1}$, Amrita Pati $^{1}$, Natalia Mikhailova ${ }^{1}$, Amy Chen ${ }^{4}$, Krishna Palaniappan ${ }^{4}$, Miriam Land ${ }^{1,5}$, Loren Hauser $^{1,5}$, Yun-Juan Chang, ${ }^{1,5}$, Cynthia D. Jeffries ${ }^{1,5}$, Patrick Chain ${ }^{1,3}$, Manfred Rohde ${ }^{6}$, Markus Göker ${ }^{2}$, Jim Bristow ${ }^{1}$, Jonathan A. Eisen ${ }^{1,7}$, Victor Markowitz ${ }^{4}$, Philip Hugenholtz ${ }^{1}$, Nikos C. Kyrpides ${ }^{1}$, Hans-Peter Klenk ${ }^{2}$, and Alla Lapidus ${ }^{1 *}$

${ }^{1}$ DOE Joint Genome Institute, Walnut Creek, California, USA

${ }^{2}$ DSMZ - German Collection of Microorganisms and Cell Cultures GmbH, Braunschweig, Germany

${ }^{3}$ Los Alamos National Laboratory, Bioscience Division, Los Alamos, New Mexico, USA

${ }^{4}$ Biological Data Management and Technology Center, Lawrence Berkeley National Laboratory, Berkeley, California, USA

${ }^{5}$ Oak Ridge National Laboratory, Oak Ridge, Tennessee, USA

${ }^{6} \mathrm{HZI}$ - Helmholtz Centre for Infection Research, Braunschweig, Germany

${ }^{7}$ University of California Davis Genome Center, Davis, California, USA

*Corresponding author: Alla Lapidus

Volume 1 No. 3, p. 310, Figure 1 should appear as shown below. The mature cell shape has previously been described as teardrop- to pear-shaped, with the attachment pole slightly pointed [1]. Our paper showed a rod-shaped cell, which is not the correct morphology for this species.

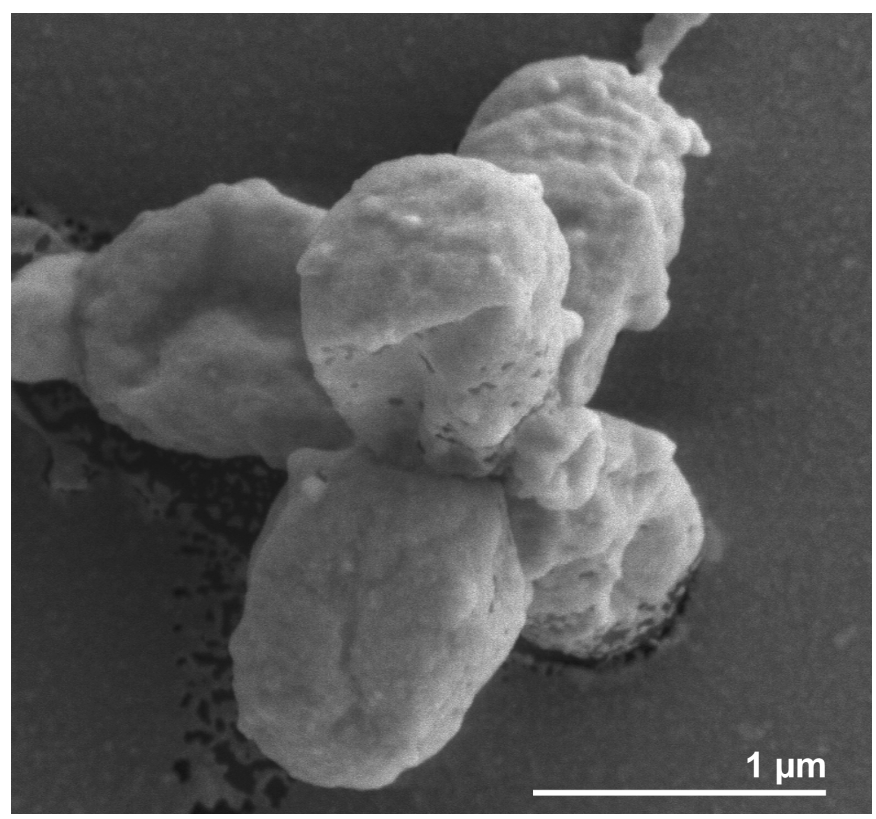

Figure 1. Scanning electron micrograph of $P$. staleyi ATCC $27377^{\top}$

\section{REFERENCES}

1. Schlesner H, Hirsch P. Assignment of ATCC 27377 to Pirella gen. nov. as Pirella staleyi comb. nov. Int J Syst Bacteriol 1984; 34:492-495. doi:10.1099/00207713-34-4-492 